\title{
Prazer e sofrimento no trabalho da equipe de enfermagem: reflexão à luz da psicodinâmica Dejouriana*
}

\author{
PLEASURE AND SUFFERING IN THE NURSING GROUP: REFLECTION TO THE \\ LIGHT OF DEJOUR PSYCHODYNAMICS
}

PLACER E SUFRIMIENTO EN EL TRABAJO DEL EQUIPO DE ENFERMERÍA: REFLEXIÓN BAJO LA VISIÓN DE LA PSICODINAMICA DEJOURIANA

Júlia Trevisan Martins ${ }^{1}$, Maria Lúcia do Carmo Cruz Robazzi², Maria Cristina Cescatto Bobroff ${ }^{3}$

\section{RESUMO}

O presente trabalho é uma reflexão teórica com o objetivo de refletir sobre as questões de vivências de prazer e sofrimento no trabalho da equipe de enfermagem, sob a ótica da psicodinâmica dejourina do trabaIho. Esta reflexão contribui para elucidar a importância dos processos organizativos no trabalho da equipe de enfermagem, em especial por considerar os aspectos relacionados à intersubjetividade e à história singular de cada ser humano. Diagnosticar as situações cotidianas no ambiente de trabaIho é importante para intervenções nas formas de organização do processo de trabaIho, bem como em outras situações que forem necessárias, contribuindo, assim, para a melhoria da qualidade de vida no ambiente laboral e na vida privada.

\section{DESCRITORES}

Enfermagem.

Condições de trabalho.

Saúde do trabalhador.

Emoções.

\begin{abstract}
The present study is a theoretical reflection which approaches the feelings of pleasure and suffering in the nursing team work in the perspective of the psychodynamic under Dejour optics. This reflection contributes to elucidate the importance of the organization processes of nursing team work, in special for considering the aspects related to the intersubjectivity and the singular history of each human being. The intervention in the health area organizations and in other institutions, consequently favors the diagnostic of the work situations, contributing for the improvement of the quality of life in the proper labor environment and also in the private life, among others.
\end{abstract}

\author{
KEY WORDS \\ Nursing. \\ Working conditions. \\ Occupational health. \\ Emotions.
}

\begin{abstract}
RESUMEN
El presente trabajo es un ensayo teórico que tuvo como objetivo reflexionar sobre las cuestiones de experiencia de placer y sufrimiento en el trabajo del equipo de enfermería bajo la óptica de la psicodinámica dejouriana del trabajo. Esta reflexión contribuye a elucidar la importancia de los procesos organizativos del trabajo del equipo de enfermería, en especial por considerar los aspectos relacionados a la intersubjetividad y a la historia singular de cada ser humano. Diagnosticar las situaciones cotidianas en el ambiente de trabajo es importante para intervenciones en los modos de organización del proceso de trabajo, así como en otras situaciones en que fuera necesario hacerlo, contribuyendo de tal modo en la mejora de la calidad de vida en el propio ambiente laboral y, consecuentemente, en la vida privada.
\end{abstract}

\section{DESCRIPTORES \\ Enfermería. \\ Condiciones de trabajo. \\ Salud ocupacional. \\ Emociones.}

\footnotetext{
* Extraído da tese "Prazer e sofrimento no trabalho do enfermeiro em Unidades de Terapia Intensiva: estratégias defensivas", Programa Interunidades de Doutoramento da Escola de Enfermagem e Escola de Enfermagem de Ribeirão Preto da Universidade de São Paulo, 2008. ${ }^{1}$ Enfermeira. Doutora em Enfermagem Fundamental. Professora Adjunta da Universidade Estadual de Londrina. Londrina, PR, Brasil. jtmartins@uel.br ${ }^{2}$ Enfermeira. Doutora em Enfermagem. Professora Titular da Escola de Enfermagem de Ribeirão Preto da Universidade de São Paulo. Ribeirão Preto, SP, Brasil. avrmlccr@eerp.usp.br ${ }^{3}$ Enfermeira. Doutora em Ciências da Saúde. Professora Convidada do Curso de Pós-Graduação em Saúde do Trabalhador, da Faculdade de Educação, Ciências e Letras de Paranavaí. Paranavaí, PR, Brasil. cris.bobroff@hotmail.com
}

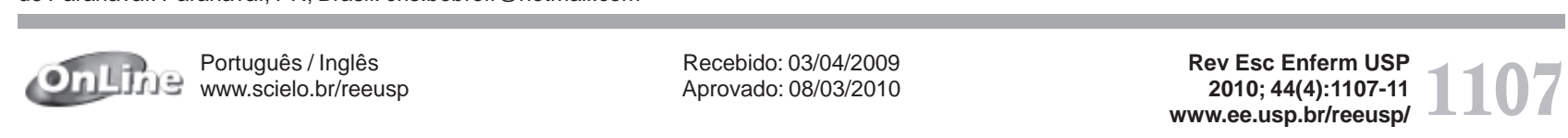




\section{INTRODUÇÃO}

Os trabalhadores da equipe de enfermagem estão inseridos no conjunto de profissionais da área de saúde. Desta forma, fazem parte da equipe multiprofissional que se responsabiliza pela assistência prestada ao indivíduo e seus familiares.

Em nossa sociedade o labor tem características de ser fragmentado pela especialização, burocratização, tendendo ao mecanicismo, executado de acordo com normas e rotinas, imbuído de exigências, às vezes obsoletas ou exageradas que podem, em muitas situações, impedir o indivíduo de se transformar e de recriar o seu trabalho ${ }^{(1)}$.

O trabalho da equipe de enfermagem tem como característica um processo organizativo influenciado pela fragmentação, ou seja, segue os princípios taylorizados e tem como objeto de trabalho o sujeito doente. Assim, esses profissionais se deparam constantemente com sofrimentos, medos, conflitos, tensões, disputa pelo poder, ansiedade e estresse, convivência com a vida e morte, longas jornadas de trabalho, entre tantos outros fatores que são inerentes ao cotidiano desses trabalhadores.

Desta forma, é imprescindível que o trabalho da equipe de enfermagem seja compreendido em todos os seus aspectos, quer sejam econômicos, culturais e sociais, sendo de fundamental importância o entendimento de questões que envolvam a produção social da subjetividade, da saúde física e da saúde mental das pessoas ${ }^{(2)}$.

Outro fator vivenciado pela equipe de enfermagem é a falta de autonomia, o que, em muitos aspectos, dificulta que se alcancem as metas assistenciais e gerenciais, entre outras. Também se percebe que na maioria das vezes os próprios trabalhadores não se permitem buscar estratégias para ultrapassar os obstáculos, podendo gerar conflitos, insatisfações, estresse, angústia e temores, que desencadeariam sentimentos de sofrimento no trabalho(3-4).

Embora o trabalho possa ser fonte de sofrimento, por outro lado, proporciona vivências de prazer, pois é por meio dele que o ser humano constrói sua vida e se insere no mundo laboral, não somente como forma de sobrevivência, mas também para realização pessoal e profissional. Assim, o trabalho possibilita o processo de formação do indivíduo, em sua produtividade técnica, política, cultural, estética e artística envolvendo a subjetividade.

Em certas condições, o resultado da relação do trabaIhador com o labor pode desencadear vivências de sofrimento. Há uma correlação entre a personalidade do indivíduo, o seu projeto individual e a prescrição do trabalho que não leva em consideração o aspecto da subjetividade inerente nesta relação(5).
O trabalho desenvolvido pela equipe de enfermagem, em especial, em unidades tidas como críticas como as Unidades de Terapia Intensiva (UTIs) e Pronto Socorro (PS) caracteriza-se por ter, como objeto de trabalho, indivíduos portadores de casos clínicos de extrema gravidade, considerados como pacientes que estão em risco de morte iminente. Assim sendo, exige-se da equipe um conjunto de domínios que englobam: pensar rápido, ter agilidade, capacidade de liderança, resolutividade de problemas, ser capaz de lidar com tecnologia de ponta, dentre outros.

Entretanto, o trabalho dos profissionais de saúde, mesmo em locais como UTIs e PS, não envolvem apenas o sofrimento. A possibilidade de aliviar a dor, de salvar vidas, de sentir-se útil, de trabalho coletivo, entre outros fatores, pode ser fonte de conforto e satisfação, que contribui para o sentimento de prazer e favorece o equilíbrio psíquico dos trabalhadores.

Diante das considerações anteriores, este estudo teórico teve como objetivo refletir sobre as questões de vivências de prazer e sofrimento no trabalho da equipe de enfermagem sob a ótica da psicodinâmica dejouriana do trabalho. Nesta perspectiva, compreende-se que a relação do homem e do trabalho está na identificação do labor como um local de produção de significações psíquicas e de construção de relações sociais, uma mediação entre o psíquico e o social, e o particular e o coletivo.

Na abordagem da psicodinâmica do trabalho faz-se necessário romper com os princípios taylorizados do labor e buscar novos paradigmas de organização do trabalho que visem à integração entre o como fazer e os resultados, bem como a descentralização das decisões, a autonomia, a flexibilidade hierárquica, a criatividade, o incentivo, a participação, a valorização e o exercício da qualificação, bem como a história singular de cada indivíduo ${ }^{(5-6)}$.

Assim sendo, compreende-se a organização do trabalho com todas as características relacionadas à institucionalização do labor, inserindo-se a filosofia da instituição, o organograma, o processo de trabalho, os produtos, as máquinas, os equipamentos, e, principalmente o trabalhador individual e coletivo com suas particularidades e especificidades.

\section{CONTEXTUALIZANDO A PSICODINÂMICA DO TRABALHO: UMA VISÃO DA PROPOSTA DE CRISTOPHE DEJOURS}

A psicodinâmica do trabalho na ótica dejouriana refere-se aos estudos dos movimentos psicoafetivos gerados pela evolução dos conflitos intersubjetivos e intra-subjetivos existentes entre a organização prescrita e a organização real do trabalho(7). 
Assim, nesta reflexão teórica, entende-se que as formas de organização do trabalho que estão pautadas, na totalidade ou parcialmente, nas bases estabelecidas pela escola científica de administração, não considera a saúde holística do trabalhador, ou seja, não trata a organização do labor como um processo dinâmico e que envolve a subjetividade dos indivíduos - a preocupação está voltada para a saúde física. Entretanto, é fundamental compreender as inter-relações do ambiente de trabalho, considerando a saúde física e mental, bem como as formas de organização do labor ${ }^{(5)}$.

Nesse sentido, a psicodinâmica dejouriana destaca que as relações humanas nas instituições são determinadas pelas diferentes formas de organização do trabalho, isto significa entender que, nos modelos organizacionais, os aspectos subjetivos do trabalhador são relevantes.

O entendimento da influência da organização do trabaIho na qualidade de vida dos trabalhadores, na geração das vivências do prazer, sofrimento, desgaste, satisfação e no adoecimento das pessoas é de suma importância para a compreensão e intervenção em várias situações de trabalho e também para superação dos modelos clássicos de organização do $\operatorname{labor}^{(8)}$.

A psicodinâmica do trabalho parte do pressuposto de que os trabalhadores possuem capacidade de se proteger, de buscar alternativas e se reapropriar da transformação e reconstrução de uma realidade que está colocada, e em especial, da forma como está organizado o processo de trabalho. Desta forma, os trabalhadores podem buscar soluções coletivas ou individuais para evitar ou amenizar os sentimentos de sofrimento ${ }^{(9)}$.

Para a psicodinâmica, é pelo processo subjetivo que se torna possível a gestão social de interpretações do trabaIho real pelos indivíduos, a criação de novos conhecimentos, fazeres e atividades, que possam contribuir para uma identificação mais lógica entre o trabalho prescrito, trabaIho real, e os investimentos pulsionais do trabalhador ${ }^{(5)}$.

Assim, na psicodinâmica do trabalho, apesar de sua referência estar diretamente ligada ao concreto, os conceitos são elaborados a partir da história singular, crenças, desejos, ponto de vista construído, como o homem vê o mundo objetivo e as tarefas a serem executadas. É na racionalidade, na ação, na organização do processo de trabalho que o sujeito busca fazer com que o trabalho não seja somente sofrimento, mas sim mediador do prazer ${ }^{(9-10)}$.

Assim sendo, o bem estar físico e o prazer são, simplesmente, a liberdade destacada no desejo de cada um na organização de sua vida e, por consequência, no trabalho; liberdade entendida sobre o conteúdo do trabalho, a divisão das tarefas e relação existente consigo mesmo e com os outros.

A maneira como é desenvolvido o trabalho em saúde implica na relação trabalhador e usuário, na redução do universo das necessidades e nos conhecimentos específicos necessários. Isto torna tal processo previsível e estruturado, podendo fazer com que seus agentes deixem de ser sujeitos e tornem-se meros cumpridores de tarefas, ao trocar a complexidade da vida pela simplicidade do raciocínio, tornando os procedimentos e atos terapêuticos eficientes em si e justificados na maioria das vezes pela frieza do rigor científico, tendo como entendimento que a saúde é o completo bem-estar físico, mental e social ${ }^{(11)}$.

Entretanto, para a psicodinâmica do trabalho, a saúde é antes de tudo, um fim, um objetivo a ser atingido, um estado do qual procuramos nos aproximar, pois o bem-estar social, psíquico e até mesmo o físico não são estáveis, de forma que, mesmo quando atingidos, não há garantia de que se possa mantê-los para sempre ${ }^{(10)}$.

A separação clássica existente entre dentro do trabalho e o fora do trabalho, é desconsiderada, pois o funcionamento psíquico não é divisível. Os profissionais de saúde não largam o seu funcionamento psíquico no vestiário; levam contrariedades mentais consigo e necessitam do círculo familiar para manter suas defesas a fim de regressar ao trabalho ${ }^{(9)}$.

No entendimento da psicodinâmica do trabalho, o convívio harmonioso com a família, consigo mesmo e com os outros, propicia relações mais fecundas no trabalho e na vida como um todo, ou seja, as interferências do labor não se restringem apenas ao ambiente de trabalho. Este repercute nas situações de trabalho, na vida familiar e na vida pessoal dos trabalhadores ${ }^{(10,12)}$.

Assim, o labor é um gerador de saúde ou, ao contrário, um constrangimento patogênico. Jamais é neutro; joga a favor da saúde ou leva o indivíduo à descompensação(13).

Sendo o labor considerado como elemento fundamental na construção do ser humano, revelando-se como mediador entre o inconsciente e o campo social, o particular e o coletivo, então, o modo como a organização do trabalho acontece, permite evidenciar que ele em si não é nocivo ou perigoso, como se fossem atributos inerentes ao mesmo. Ao contrário, o que pode torná-lo com essas características é a maneira como o mesmo é organizado pelos indivíduos.

Desta forma, novas concepções de organização do trabaIho devem ser buscadas. Há que se estabelecer um compromisso que seja negociado entre quem organiza e quem o executa, assim, pode ocorrer uma evolução e transformação que mudam desde as instalações físicas da instituição até as relações de trabalho. Tal organização é uma relação social, um compromisso entre as metas a serem atingidas, os procedimentos e as dificuldades reais para a execução do labor.

Em estudo realizado com enfermeiras de UTIs ${ }^{(14)}$ evidenciou-se que a forma de organização do setor foi facilitadora da assistência prestada ao paciente e propiciou maior segurança às enfermeiras. No mesmo estudo, as profissionais informaram que os esforços para assistir os pacientes em contato direto eram compensados pela sensação de ser útil e de estar cumprindo o dever assumido com os mais fracos e dependentes, isto é, mesmo diante dos esforços, houve sentimentos de prazer. 
Com esse entendimento, ao organizar-se um trabalho, deve-se partir da premissa que o mesmo é uma ação de reflexão coletiva, da qual os trabalhadores devem participar como agentes ativos e não como meros espectadores.

O exercício da reflexão coletiva supõe discussões em conjunto, uma finalidade da apropriação de uma inteligibilidade comum, conduzida pela compreensão de acordos, normas e de novas regras no trabalho. Para isso, é fundamental a criação de espaço em que as pessoas possam se expressar e ouvir, para que a transformação do processo de organização do trabalho realmente pode ocorrer ${ }^{(15)}$.

Ao se entender que o trabalhador é capaz de pensar, de verbalizar suas idéias e chegar a uma interpretação, pode se propiciar a abertura para a negociação, para buscar novas propostas, e, assim, fazer com que o processo de organização do labor se desenvolva conjuntamente. Isto não significa que o mesmo está isento de trazer sofrimentos, insatisfação, tensões, entre outros, porém, ao se estabelecer esta abertura há possibilidades de negociação a qualquer momento, de transformar e de recriar novos processos de trabalho que atendam às reais necessidades dos trabalhadores, da instituição e dos usuários.

Para a psicodinâmica do trabalho, é no coletivo que se constrói o sentido dos sofrimentos vivenciados e é por meio das ações comunicativas que se compartilham os sentimentos. Assim, ao se propiciar um espaço para que os trabalhadores compartilhem seus sentimentos, no qual possa se criar uma linguagem comum que leve a uma nova inteligibilidade, à nova interpretação e a um novo sentido para o trabalho, proporciona-se um efeito positivo no processo das relações de cooperação e de troca de conhecimentos que, por sua vez, repercutem nos sentimentos de prazer dos indivíduos ao desenvolver suas atividades laborativas ${ }^{(15)}$.

Entretanto, para se falar é preciso ouvir antes de tudo, para não quebrar a dinâmica criada em um espaço aberto de organização do trabalho para a criatividade e a iniciativa. Para isso, faz-se necessário que os depoimentos aconteçam em todos os níveis hierárquicos e em relação de igualdade. Pressupõe-se que os que falam devem estar prontos, como os que o ouvem. É preciso coragem de ambos os lados, pois para quem fala, é muito difícil dizer o que se está fazendo, principalmente quando se desenvolve o trabalho com certo distanciamento dos procedimentos prescritos, mas apenas a coragem de se arriscar tornam-se visíveis e inteligíveis os componentes fundamentais do labor ${ }^{(16)}$.

Outro fator a considerar em relação aos sentimentos de sofrimento vivenciados pela equipe de enfermagem, é o fato de se lidar com o sofrimento e a dor dos indivíduos e a convivência diária com a morte, que pode levar os profissionais a um crescente estresse, decorrente do trabalho, pois isto contraria os seus objetivos que é o de salvar vidas. Os profissionais carecem de preparo para lidar com as questões relacionadas com a morte e o processo de morrer, pois este é um tema que é pouco abordado nas escolas e nas instituições de saúde ${ }^{(17-19)}$.

Com os fundamentos apresentados, pode-se inferir que os sentimentos de prazer e sofrimento são basicamente determinados pela dinâmica estabelecida entre a organização do trabalho e a história de vida do trabalhador, isto é, seu significado de vida no trabalho e sua vida privada.

Não há regras ou receitas para que os trabalhadores maximizem os sentimentos de prazer e minimizem os sentimentos de sofrimento. Entretanto, é imprescindível que os trabalhadores estejam comprometidos com as suas tarefas e lhes atribuam significados, bem como é fundamental criar espaços para discutir e espaços para convivência, cujos desafios não podem se restringir aos problemas técnicos, científicos ou relacionados às atividades produtivas, mas também direcionados à convivência humana, para oportunizar o viver comum. As regras de sociabilidade favorecem o mundo social do trabalho, protegendo o ego e, por sua vez, colaborando para uma subjetividade saudável entre os profissionais de enfermagem, bem como de áreas afins ${ }^{(15)}$.

Desta forma, é essencial estabelecer o diálogo, porém, não um diálogo de cunho do verbalismo, mas aquele que busca trocar idéias, que seja liberador, que implica em assumir compromissos, comprometendo-se consigo mesmo e com os outros, na busca incessante de ações transformadoras para os trabalhadores, na tentativa de melhorar a sua qualidade de vida e ,por consequência, no melhor atendimento aos usuários e seus familiares e também para a instituição envolvida.

\section{CONSIDERAÇÕES FINAIS}

No presente estudo ficou evidenciado que o trabalho, na visão da psicodinâmica do trabalho dejouriana, está diretamente relacionado com as situações vivenciadas na realidade cotidiana dos trabalhadores, sendo que a forma de organização do trabalho e o ser humano não deve ser um conjunto rígido, mas deve estar pautado na flexibilidade. Para que ocorra a estabilidade desta relação, deve-se permitir a evolução e as transformações, pois se as formas de organização laboral forem bloqueadas, travadas ou cristalizadas, impedem o crescimento dos trabalhadores, podendo surgir ineficiências no trabalho, conflitos, tensões, estresses, sentimentos de sofrimento, dentre outros.

Por outro lado, se a relação do homem com o processo organizacional das atividades for favorável, o trabalho pode proporcionar vivências de prazer. Porém, para que isso ocorra é necessário que as atividades correspondam às aspirações do trabalhador e que propiciem maneiras de se expressar a subjetividade, participando da organização do processo laboral, modificando-o, para que atenda às reais necessidades de todos os envolvidos nesse processo.

O trabalho desenvolvido pela equipe de enfermagem é gerador de sentimentos ambíguos, ora ele pode colaborar para vivências de prazer ora para vivências de sofrimento. Isto se dá porque há possibilidade de ser útil enquanto servem, ajudam e confortam. Porém, ao se deparar com o sofrimento alheio, com a morte, com a dor e/ou situações difíceis de serem superadas, o trabalhador também sofre.

Além disso, o fato desses profissionais terem sido preparados, nos cursos de graduação, para salvar vi- 
das, o que muitas vezes não ocorre, gera vivências de sofrimento.

É importante, então, que os profissionais de enfermagem entendam que o sofrimento e o prazer são sentimentos dialéticos no trabalho e sua compreensão é de grande relevância para a promoção da saúde dos trabalhadores e para a melhoria da qualidade da assistência prestada. O conhecimento dos fatores causadores de prazer e sofrimento pode ser o ponto de partida para que as organizações e os próprios trabalhadores impulsionem o labor em um sentido mais prazeroso e colaborativo e, consequentemente, mais humano para si mesmos. Pode-se, assim, evitar doenças quer sejam físicas ou psíquicas, relacionadas ao sofrimento no trabalho.

Acredita-se que esta reflexão teórica, pautada na psicodinâmica do trabalho, possa colaborar para elucidar e/ou rea-

\section{REFERÊNCIAS}

1. Gutierrez BAO, Ciampone MHT. O processo de morrer e a morte no enfoque dos profissionais de enfermagem de UTIs. Rev Esc Enferm USP [periódico na Internet]. 2007 [citado 2010 jan. 21];41(4):[cerca de 7 p]. Disponível em: http:// www.scielo.br/pdf/reeusp/v41n4/16.pdf

2. Trevisan MJ, Robazzi MLCC, Garanhani ML. Sentimentos de prazer entre enfermeiros de unidades de terapia intensiva. Ciênc Enferm [periódico na Internet]. 2009 [citado 2010 jan. 21];15(3).[cerca de 9 p.]. Disponível em: http://www.scielo.cl/ pdf/cienf/v15n3/art_06.pdf

3. Leopardi MT. Processo de trabalho em saúde: organização e subjetividade. Florianópolis: Papa Livros; 1999.

4. Martins JT. Prazer e sofrimento no trabalho do enfermeiro em Unidades de Terapia Intensiva: estratégias defensivas [tese]. Ribeirão Preto: Escola de Enfermagem de Ribeirão Peto, Universidade de São Paulo; 2008.

5. Dejours C. A loucura do trabalho: estudo de psicopatologia do trabalho. 5a ed. São Paulo: Cortez; 1992.

6. Mendes AM, Abrahão Jl. Organização do trabalho e vivências de prazer-sofrimento do trabalhador: abordagem psicodinâmica. Rev Psicol Teoria Pesq. 1996;12(2):179-84.

7. Mendes AM. Psicodinâmica do trabalho: teoria, método e pesquisas. São Paulo: Casa do Psicólogo; 2007.

8. Dejours C. Uma nova visão do sofrimento humano nas organizações. In: Chanlant JT, organizador. O indivíduo na organização: dimensões esquecidas. São Paulo: Atlas 1993. p. 45-65.

9. Lancman S, Sznelwar LI, organizadores. Christophe Dejours: da psicopatologia à psicodinâmica do trabalho. Rio de Janeiro: FIOCRUZ; 2004.

10. Dejours C. Por um novo conceito em saúde. Rev Bras Saúde Ocup. 1986;54(14):7-11. firmar a importância dos processos organizativos do trabalho dentro das organizações que envolvem a equipe de enfermagem, em especial, por considerar os aspectos relacionados à intersubjetividade e à história singular de cada ser humano.

Esta reflexão apresenta limitações, por se tratar de um tema complexo que envolve diversas variáveis, porém considera-se que seja de real valia para despertar a atenção sobre a psicodinâmica do trabalho como uma possibilidade efetiva de ser um referencial importante para auxiliar em novos paradigmas de processo organizativo da enfermagem. Apesar de já haver vários pesquisadores que desenvolvem estudos com a psicodinâmica do trabalho sob a luz dejouriana, é fundamental que ainda sejam realizados maior número de estudos nesta abordagem, para que se possa possibilitar a aplicação de um modelo dinâmico de intervenção nas organizações da área de saúde e de outras instituições.

11. Merhy EE, Cecílio LCO, Nogueira RC. Por um modelo tecnoassistencial da política de saúde em defesa da vida. In: 9a Conferência Nacional de Saúde; 1992 out. 10-13; Brasília, BR. Brasília: GTTCO; 1992. p. 30.

12. Beck CLC, Budó ML, Gonçalves RMB. A qualidade de vida na concepção de professores de enfermagem: elementos para reflexão. Rev Esc Enferm USP. 1999;33(4):348-54.

13. Dejours C. Subjetividade, trabalho e ação. Rev Produção. 2004;14(3):27-34.

14. Shimizu HE, Ciampone MHT. Sofrimento e prazer no trabaIho vivenciado pelas enfermeiras que trabalham em Unidades de Terapia Intensiva em um Hospital Escola. Rev Esc Enferm USP. 1999;33(1):95-106.

15. Dejours C. Conferências brasileiras: identidade, reconhecimento e transgressão no trabalho. São Paulo: FUNDAP; 1999.

16. Ferreira MC, Mendes AM. Só de pensar em vir trabalhar já fico de mau humor: atividade de atendimento ao público e prazer-sofrimento no trabalho. Rev Psicol. 2001;6(1):93-104.

17. Oliveira JR, Brêtas JRS, Yamaguti L. A morte e o morrer segundo representações sociais de estudantes de enfermagem. Rev Esc Enferm USP. 2007;41(3):386-94.

18. Bernieri J, Hides A. O preparo de acadêmicos de enfermagem brasileiros para viverem o processo da morte e morrer. Texto Contexto Enferm. 2007;16(1):89-96.

19. Santana JCB, Leal AC, Lopes PAT, Guimarães RG. Percepções de acadêmicos de enfermagem sobre finitude em instituições hospitalares. Rev Enferm UFPE On-Line [periódico na Internet]. 2010 [citado 2010 jan. 25];4(1):[cerca de 5 p]. Disponível em: http://www.ufpe.br/revistaenfermagem/ index.php/revista/issue/view/16 